\title{
Complex Regional Pain Syndrome Treated with Intravenous Immunoglobulin in a Patient with Common Variable Immune Deficiency
}

Raffi Tachdjian

To view enhanced content go to www.paintherapy-open.com

Received: September 23, 2013 / Published online: December 5, 2013

(c) The Author(s) 2013. This article is published with open access at Springerlink.com

\section{ABSTRACT}

Introduction: Common

variable

immunodeficiency (CVID) represents a large heterogeneous group of antibody-deficiency syndromes associated with a wide range of clinical features and a lack of defined causes in the realm of primary immunodeficiencies. Here, we present a case of CVID in a 62-year-old white male patient with a history of longstanding complex regional pain syndrome (CRPS).

Case Presentation: His medical history included multiple sinus infections per year and several pneumonias requiring antibiotics. He has had various back surgeries, including a

R. Tachdjian $(\bowtie)$

Division of Clinical Immunology and Allergy, David Geffen School of Medicine at UCLA,

Los Angeles, CA, USA

e-mail: UCLAdoc@gmail.com;

RTachdjian@mednet.ucla.edu

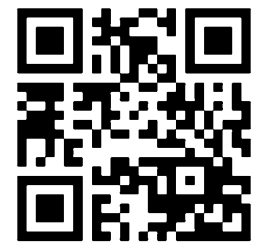

Enhanced content for this article is available on the journal web site: www.paintherapy-open.com laminectomy at the L4 level 1 year prior to his diagnosis. Thereafter, he underwent four sympathetic nerve blocks with minimal pain relief. Blood chemistries showed a normal white blood cell count with a normal differential, but increased erythrocyte sedimentation rate and C-reactive protein levels. Total Ig (Immunoglobulin)G was $611 \mathrm{mg} / \mathrm{dL}$ (normal 700-1,600), IgG1 was $425 \mathrm{mg} / \mathrm{dL}$ (341-894), IgG2 was $114 \mathrm{mg} / \mathrm{dL}$ (171-632), IgG3 was $14.4 \mathrm{mg} / \mathrm{dL}$ (18.4-106), and IgG4 was $7.4 \mathrm{mg} /$ dL (2.4-121). IgA was $47 \mathrm{mg} / \mathrm{dL}$ (normal 70-400), IgM was $131 \mathrm{mg} / \mathrm{dL}$ (40-230), and IgE was $4.5 \mathrm{kU} / \mathrm{L}(<4.0)$. He only had 10 of 23 pneumococcal titers in the protective range post-vaccination. Upon treatment of the CVID with intravenous immunoglobulin, the patient's pain levels were significantly decreased and have been maintained for more than 2 years.

Conclusion: Therefore, immunoglobulin therapy appears to have been beneficial in the treatment of the patient's symptoms of CRPS, including pain. Additional studies investigating the mechanism by which immunoglobulin therapy may reduce the inflammation and pain of CRPS are needed. 
Keywords: Common variable immune deficiency; Complex regional pain syndrome; Intravenous immunoglobulin; Pain

\section{INTRODUCTION}

Complex regional pain syndrome (CRPS) is a condition characterized by continuing regional pain that is seemingly disproportionate in the time or degree to the usual course of pain after trauma or other lesion [1-3]. Previously called reflex sympathetic dystrophy (CRPS Type I) or causalgia (Type II), CRPS occurs with or without definable nerve lesions, respectively. CRPS typically involves abnormal sympathetic, sensory, motor, sudomotor, vasomotor edema, and/or other trophic findings that may occur after an injury or surgical procedure, but frequently there is no ensuing event $[1,3]$. Clinical features such as burning pain with allodynia and hyperalgesia with changes in skin temperature also occur in the affected limb. CRPS can strike at any age and affects both men and women equally [4].

Common variable immunodeficiency (CVID) is the most common, symptomatic primary immunodeficiency $[5,6]$ and affects 1 in 50,000 to 1 in 75,000 individuals [7]. CVID can be diagnosed in both children and adults, and is hallmarked by two low isotypes of immunoglobulin (i.e., IgG and IgA) along with low specific antibody response. The disease can result in serious and recurrent bacterial and viral infections of the ears, sinuses, nose, bronchi, and lungs and is associated with increased frequency of infections, autoimmune disease, gastrointestinal and pulmonary disease, hepatitis, lymphoma, and other cancers [5, 710]. Individuals with CVID may not receive a diagnosis until later in life because the symptoms of antibody deficiency may not become obvious until then [5].
Because of the varied illnesses and symptoms that may appear, individuals with CVID may receive medical care from physicians in a variety of clinical specialties often leading to delayed diagnosis. The following case involves a patient with an undiagnosed immune deficiency that, when treated, appeared to help with his original pain complaint.

\section{CASE PRESENTATION}

A 62-year-old white male with a 2-year history of CRPS of his right lower extremity, without inciting injury, presented to our immunology clinic for evaluation. The patient previously reported symptoms consistent with CRPS diagnosed by his rheumatologist, including continuing pain that was disproportionate to any inciting event, as well as allodynia (to light touch), edema, and decreased range of motion and motor dysfunction (e.g., weakness, tremor, dystonia). He has also been followed by his rheumatologist for the diagnosis of Sjögren's syndrome and Rheumatoid Arthritis. In our clinic, he described a gripping pain, different from arthritic pain, from his right knee area to his ankle that was without any swelling, pruritus, or dermatitis. The pain was worse in the anterior region than in the posterior regions around his knee. Allodynia below the knee was so severe in that region that he would wear a leg "tunnel" to avoid contact with his blanket at night. His medical regimen to control the pain included gabapentin $300 \mathrm{mg} 3$ times daily, abatacept $750 \mathrm{mg}$ intravenously weekly, and hydrocodone/acetaminophen 5/500 mg every $8 \mathrm{~h}$ as needed.

The patients' medical history included multiple sinus infections per year and 6 lifetime pneumonias requiring antibiotics. He was hospitalized twice for pneumonia while 
serving in the army. He has had various back surgeries, including a laminectomy at the L4 level, 1 year prior to his diagnosis. There were no bony changes on imaging of the lower extremity. Shortly after the laminectomy, he underwent 4 sympathetic nerve blocks with minimal pain relief.

He is retired, denied any illegal drug or alcohol use, and reported a non-contributory family or social history. He has no children and his parents are deceased. On physical examination, his vital signs were all within the normal range. His gait was antalgic with a cane, and he was overweight, with a body mass index of 32 . His hair, skin, and dentition appeared normal with no ulcers in the oral cavity. Cardiac, pulmonary, and abdominal examinations were unremarkable. His extremities were warm and well-perfused, although he had noticeable tenderness to palpation of the right shin and knee regions. The calf measurements were $38 \mathrm{~cm}$ at their peak on both legs. His strength was 4 out of 5 (with a 5 being the maximum strength) in the right knee and 5 out of 5 on the left; reflexes and joints were normal without cyanosis or dermatitis.

Blood chemistries included a white blood cell count of $7.7 \mathrm{~K} / \mu \mathrm{L}$ (normal 4-11) with a normal differential, erythrocyte sedimentation rate (ESR) was $28 \mathrm{~mm} / \mathrm{h}$ (normal 0-15), and C-reactive protein was $1.6 \mathrm{mg} / \mathrm{dL}$ (normal <1.0). Total IgG was $611 \mathrm{mg} / \mathrm{dL}$ (normal 700-1,600), IgG1 was $425 \mathrm{mg} / \mathrm{dL}$ (341-894), IgG2 was $114 \mathrm{mg} / \mathrm{dL}$ (171-632), IgG3 was $14.4 \mathrm{mg} / \mathrm{dL}$ (18.4-106), and IgG4 was $7.4 \mathrm{mg} / \mathrm{dL}$ (2.4-121). IgA was $47 \mathrm{mg} / \mathrm{dL}$ (normal 70-400), IgM was $131 \mathrm{mg} / \mathrm{dL}$ (normal 40-230), and IgE was $4.5 \mathrm{kU} / \mathrm{L}$ (normal $<4.0$ ). A total of $10 / 23$ postvaccination, pneumococcal serotype titers were in the protective range. Complement $\mathrm{C} 4$ was $27 \mathrm{mg} / \mathrm{dL}$ (normal 14-44). Anti-nuclear antibodies, as well as, anti-Sm, anti-RNP, anti-
SSA and SSB, anti-Scl70, and anti-Jo1 were all negative.

Upon diagnosis of CVID, the patient was started on intravenous immunoglobulin (IVIG) $500 \mathrm{mg} / \mathrm{kg}$ monthly. Physical therapy was begun thereafter, and as little as 1 day after initial and subsequent infusions, the patient reported a dramatic decrease in lower extremity pain. He reported feeling the pain remounting by the 4th week after each infusion, but overall this seems to be more tolerated than in the past. On a 0-10 numeric pain intensity scale (with 10 being the most severe pain), his right leg pain decreased significantly from 7 out of 10 to 2 out of 10 , and the patient reported a significant increase in energy. Strength was reported as 5 out of 5 in each knee. Initially, calf measurements were $37.5 \mathrm{~cm}$ on the right and $38 \mathrm{~cm}$ on the left. At 1-year follow-up, both right and left calf measurements were $37 \mathrm{~cm}$.

Informed consent was obtained from the patient for being included in the study.

\section{DISCUSSION}

Common variable immunodeficiency represents a large heterogeneous group of antibody-deficiency syndromes associated with a wide range of clinical features and a lack of defined causes in the realm of primary immunodeficiencies. While the benefit of immunoglobulin replacement to treat CVID is well-known and current practice guidelines support the use of subcutaneous or IVIG to treated patients with CVID, the efficacy of IVIG in the treatment of inflammation and pain caused by CRPS is not yet as definitive and supportive data is limited.

A study by Goebel et al. [11] investigated the efficacy of IVIG therapy in a small cohort of patients who had pain intensity greater than 4 
on an 11-point pain scale and had CRPS for 6-30 months refractory to standard treatment. For the 12 patients who completed the 4 -week trial, IVIG $500 \mathrm{mg} / \mathrm{kg}$ significantly reduced the average pain intensity $1.55 \mathrm{U}$ in comparison with treatment with saline $(P<0.001)$. In addition, a total of 3 patients had median pain scores that were lowered by $50 \%$. Despite several limitations to the study, including the trial size, the authors showed that there was a significant reduction in pain associated with CRPS as a result of IVIG treatment [12].

In the United States, one indicated use of IVIG is to relieve pain associated with chronic inflammatory demyelinating polyneuropathy [12]. Although the mechanism is not fully understood and may differ among pain syndromes, there are also a few pilot studies and clinical trials that have investigated the use of IVIG in the treatment of pain associated with Stiff-Person syndrome [13, 14], post-polio syndrome [15-17], and refractory neuropathic pain [18]. A phase $1 / 2$ trial investigating the use of IVIG in treating acute pain in sickle cell disease is currently recruiting [19].

Here, we have presented the case of a male previously diagnosed with CRPS who subsequently was found to have CVID diagnosed by a low IgA and IgG and suboptimal pneumococcal antibody titers prompted by a history of recurrent sinopulmonary bacterial infections. The patient's age at time of CVID diagnosis should be noted as it highlights the matter of diagnostic delay despite a history of recurrent respiratory infections. Upon initiation of IVIG therapy using the immune deficiency dosing (for this patient $500 \mathrm{mg} / \mathrm{kg}$ monthly), the patient's pain levels were significantly decreased and have remained suppressed for more than 2 years. The patient was also diagnosed with rheumatoid arthritis and Sjögren's syndrome by his rheumatologist, which was not surprising due the increased prevalence of autoimmune diseases in CVID patients [8-10, 20]. Since CRPS is not known to do so, these co-existing autoimmune diagnoses most likely account for the elevated inflammatory markers as evidenced by the increased ESR and C-reactive protein.

In addition, due to the increased incidence of malignancy in CVID patients [in particular, gastrointestinal (GI)], the patient was referred to a GI specialist for the follow-up.

The patient continues physical therapy with aquatherapy once a week and uses a transcutaneous electrical nerve stimulation unit regularly on his leg and back. The pain level ( 2 out of 10 ) for the patient has been maintained, and from as little as 1 day after each infusion he has reported a complete absence of pain. The patient also has had no bacterial infections since starting IVIG treatment, feels more energetic, and ambulates with greater ease.

\section{CONCLUSION}

Upon treatment of the CVID with IVIG therapy, the patient's pain levels due to CRPS were significantly decreased and have been maintained for more than 2 years. Therefore, immunoglobulin therapy appears to be beneficial in the treatment of CRPS symptoms, including pain. When treating patients with CRPS and signs of immunodeficiencies such as recurrent sino-pulmonary disease, pain specialists should work them up with immunologic laboratory testing, or refer to an immunologist. Although the treatment for autoimmune inflammatory conditions respond to high doses of immunoglobulin therapy (usually $2 \mathrm{~g} / \mathrm{kg}$ IV monthly), our patients' CRPS symptoms have responded to the lower 
immunodeficiency dose $(400-600 \mathrm{mg} / \mathrm{kg}$ IV monthly), according to guidelines used in treating his CVID. Additional studies investigating the mechanism by which immunoglobulin therapy may reduce the inflammation and pain in CRPS are needed.

\section{ACKNOWLEDGMENTS}

No funding or sponsorship was received for this study or publication of this article. Dr Tachdjian is the guarantor for this article, and takes responsibility for the integrity of the work as a whole.

Conflict of interest. Dr. Tachdjian has received speaker honoraria from Baxter, USA.

Compliance with ethics guidelines. Informed consent was obtained from the patient for being included in the study.

Open Access. This article is distributed under the terms of the Creative Commons Attribution Noncommercial License which permits any noncommercial use, distribution, and reproduction in any medium, provided the original author(s) and the source are credited.

\section{REFERENCES}

1. International Association for the Study of Pain. Classification of chronic pain: 2nd edn (Revised) Part II, Section A. Relatively generalized syndromes, complex regional pain syndromes, 2012. p. 4-7.

2. Marinus J, et al. Clinical features and pathophysiology of complex regional pain syndrome. Lancet Neurol. 2011;10(7):637-48.

3. Harden RN, et al. Proposed new diagnostic criteria for complex regional pain syndrome. Pain Med. 2007;8(4):326-31.
4. de Mos M, Huygen FJ, Dieleman JP, et al. Medical history and the onset of complex regional pain syndrome (CRPS). Pain. 2008;139(2):458-66.

5. Cunningham-Rundles C. Common variable immunodeficiency. Curr Allergy Asthma Rep. 2001;1(5):421-9.

6. Spickett GP, et al. Common variable immunodeficiency: how many diseases? Immunol Today. 1997; 18(7):325-8.

7. Bonilla FA, et al. Practice parameter for the diagnosis and management of primary immunodeficiency. Ann Allergy Asthma Immunol. 2005;94(5 Suppl 1):S1-63.

8. Agarwal S, Cunningham-Rundles C. Autoimmunity in common variable immunodeficiency. Curr Allergy Asthma Rep. 2009;9(5):347-52.

9. Lin LH, et al. Common variable immunodeficiency mimicking rheumatoid arthritis with Sjogren's syndrome. J Microbiol Immunol Infect. 2005;38(5): 358-60.

10. Swierkot J, et al. Rheumatoid arthritis in a patient with common variable immunodeficiency: difficulty in diagnosis and therapy. Clin Rheumatol. 2006;25(1):92-4.

11. Goebel A, et al. Intravenous immunoglobulin treatment of the complex regional pain syndrome: a randomized trial. Ann Intern Med. 2010;152(3): 152-8.

12. Patwa HS, Chaudhry V, Katzberg H, Rae-Grant AD, So YT. Evidence-based guideline: intravenous immunoglobulin in the treatment of neuromuscular disorders: report of the Therapeutics and Technology Assessment Subcommittee of the American Academy of Neurology. Neurology. 2012;78(13):1009-15.

13. Amato AA, Cornman EW, Kissel JT. Treatment of stiff-man syndrome with intravenous immunoglobulin. Neurology. 1994;44(9):1652-4.

14. Karlson EW, et al. Treatment of stiff-man syndrome with intravenous immune globulin. Arthritis Rheum. 1994;37(6):915-8.

15. Gonzalez $\mathrm{H}$, et al. Intravenous immunoglobulin for post-polio syndrome: a randomised controlled trial. Lancet Neurol. 2006;5(6):493-500.

16. Werhagen L, Borg K. Effect of intravenous immunoglobulin on pain in patients with postpolio syndrome. J Rehabil Med. 2011;43(11):103840 . 
17. Gonzalez $\mathrm{H}$, et al. Intravenous immunoglobulin treatment of the post-polio syndrome: sustained effects on quality of life variables and cytokine expression after one year follow up. J Neuroinflamm. 2012;9:167.

18. Jann S, et al. Efficacy and safety of intravenous immunoglobulin as adjuvant treatment for refractory neuropathic pain. Results of an openlabel, multicenter study. Pain Med. 2012;13(10): 1334-41.
19. Clinicaltrials.gov: Intravenous gammaglobulin for sickle cell pain crises. 2013. http://clinicaltrials.gov/ show/NCT00644865. Last Accessed 10 Sept 2013.

20. Samson M, et al. Diagnostic strategy for patients with hypogammaglobulinemia in rheumatology. Joint Bone Spine. 2011;78(3):241-5. 